\title{
miR-146a Expression Level as a Novel Putative Prognostic Marker for Acute Promyelocytic Leukemia
}

\author{
Lan Xu, Hua Zhong, Haixia Wan, Fang-yuan Chen, Jihua Zhong, \\ Fei Xiao, Jia Liu, and Lijing Shen \\ Department of Hematology, Ren Ji Hospital, School of Medicine, Shanghai Jiao Tong University, Shanghai 200127, China \\ Correspondence should be addressed to Hua Zhong; zhh_lj@hotmail.com
}

Received 25 April 2014; Revised 13 July 2014; Accepted 15 July 2014; Published 5 August 2014

Academic Editor: Esperanza Ortega

Copyright (c) 2014 Lan Xu et al. This is an open access article distributed under the Creative Commons Attribution License, which permits unrestricted use, distribution, and reproduction in any medium, provided the original work is properly cited.

\begin{abstract}
Background. Although the curative rate for acute promyelocytic leukemia (APL) has been improved over decades, long-term prognosis is still poor. The genetic pathways that regulated cell lineage fate during the development of APL remain unclear. Methods. We investigated the correlations of miR-146a expression with its target gene Smad4 and the biological behaviors of $\mathrm{NB}_{4}$ cells. We also analyzed their expression in clinical samples from APL patients. Results. miR-146a influenced apoptosis and proliferation in $\mathrm{NB}_{4}$ cells. $m i R-146 a$ influenced endogenous Smad4 protein levels in APL cells. miR-146a expression levels were positively correlated with white cell counts and PML/RAR $\alpha$ fusion protein expression. miR-146a expression levels were negatively correlated with Smad 4 protein and the helper $\mathrm{T}$ cell (Th)/the suppressor $\mathrm{T}$ cell (Ts) ratio in these patients. Conclusions. These findings indicated that $m i R-$ $146 a$ played an important role in the development of APL in part through the repression on Smad4 protein expression. miR-146a functioned as an oncogene and may be a novel prognostic biomarker in APL.
\end{abstract}

\section{Introduction}

Acute promyelocytic leukemia (APL) has been identified as an $\mathrm{M}_{3}$ subtype of acute myelogenous leukemia (AML) by the French-American-British (FAB) classification. APL is characterized by maturation arrest at the promyelocytic stage $[1]$. A specific $t(15 ; 17)$ chromosomal translocation encodes a promyelocytic leukemia (PML) and retinoic acid receptor- $\alpha(\mathrm{RAR} \alpha)$ fusion protein to form PML/RAR $\alpha$, an oncogenic protein found in approximately $10 \%-25 \%$ of adults with AML [2]. PML/RAR $\alpha$ interferes with the process of myeloid differentiation by repressing the transcription of retinoid acid- (RA-) responsive genes.

Although the outcomes of APL have been dramatically improved since the successful introduction of alltrans retinoic acid (ATRA), arsenic acid, and combined anthracycline-based chemotherapy, more than $10 \%$ of newly diagnosed APL patients die of the disease; moreover, the 5 -year cumulative incidence of relapse is around $15 \%$ in high-risk subgroups [3]. Furthermore, the specific genes and pathways that regulate lineage fate during APL development remain unclear.

MicroRNAs (miRNAs) are a group of highly conserved non-protein-coding RNAs comprised of about 19-25 nucleotides. miRNAs can regulate the expression of a variety of genes by binding the $3^{\prime}$ untranslated regions ( $3^{\prime}$ UTRs) of messenger RNAs (mRNAs) in a sequence-specific manner to regulate mRNA translation or degradation in eukaryotic cells [4], ultimately affecting cell proliferation, apoptosis, development, and differentiation [5].

miR-146a was first identified as having a role in the innate immune and inflammatory response to microbial infection [6]. Later studies showed that $m i R-146 a$ is expressed at relatively high levels in bone marrow (BM) $\mathrm{CD} 34^{+}$progenitors from healthy donors but is found at low levels in AML patients and even lower levels in monocytes, granulocytes, erythrocytes, and megakaryocytes from the peripheral blood or BM of healthy donors [7]. miR-146a is strongly upregulated during megakaryopoiesis in mice [8], and dysregulation of $m i R-146 a$ has been found in APL cells following retinoic 
acid (RA) induction [9-12]. Our previous study confirmed the reduced expression of miR-146a in $\mathrm{NB}_{4}$ cells following treatment with ATRA [13]. However, the role of miR-146a in the clinical progression of APL remains unknown.

In this study, we investigated the correlations of $m i R-146 a$ expression with the expression of its target gene Smad4 and the biological behaviors of $\mathrm{NB}_{4}$ cells, such as proliferation and apoptosis. To further elucidate the role of miR-146a in APL, we analyzed its expression in samples from 32 APL patients for whom clinical data were available. Interestingly, the expression levels of $m i R-146 a$ were positively correlated with white blood cell (WBC) counts in the peripheral blood and expression of the PML/RAR $\alpha$ fusion protein. miR-146a expression levels were also negatively correlated with Smad4 protein and the helper $\mathrm{T}$ cell (Th)/the suppressor $\mathrm{T}$ cell (Ts) ratio in these patients. These results indicated that miR-146a functioned as an oncogene in APL and may be a potential biomarker for malignancy.

\section{Materials and Methods}

2.1. Cell Culture and Transient Transfection with miR-146a Mimics. The human promyelocytic cell line $\mathrm{NB}_{4}$ was a gift from Shanghai Institution of Hematology and was cultured in RMPI 1640 medium with $10 \%$ fetal calf serum (FCS; Gibco, $\mathrm{BRL}, \mathrm{UK})$ at $37^{\circ} \mathrm{C}$ in a $5 \% \mathrm{CO}_{2}$ humidified incubator. On the day of transfection, $5 \times 10^{6}$ cells $/ \mathrm{mL}$ were plated in 6 well plates with RMPI 1640 supplemented with 10\% FBS. Transfections were carried out with $100 \mathrm{nM}$ DMEM-diluted pre-miR miR-146a precursor, pre-miR negative control, antipre-miR miR-146a precursor, or anti-pre-miR negative control (Ambion, Carlsbad, CA, USA) using siPORT NeoFX Transfection Agent (Ambion, Carlsbad, CA, USA). Twentyfour hours after transfection, the medium was replaced, and the cells were cultured for another $24 \mathrm{~h}$. To monitor the transfection efficiency of the miRNAs, pre-miR has-miR1 precursor and anti-miR has-let-7c miRNA inhibitor were transfected into $\mathrm{NB}_{4}$ cells in parallel experiments according to the manufacturer's instructions.

2.2. Cell Proliferation, Apoptosis, and Cell Cycle Analyses. Live cell proliferation assays were carried out by trypan blue dye exclusion using a Bio-Rad automatic cell counter (Bio-Rad, Berkeley, CA, USA). The number of $\mathrm{NB}_{4}$ cells was calculated in triplicate after 24 or $48 \mathrm{~h}$ of culture.

Apoptotic cells were detected with an Alexa Fluor 488 annexin V/Dead cell apoptosis kit (Invitrogen, Carlsbad, CA, USA) by flow cytometry (BD Biosciences, Franklin Lakes, NJ, USA). Early apoptotic cells were defined as Annexin-Vpositive/propidium iodide- (PI-) negative cells. The experiments were repeated 3 times.

For analysis of the cell cycle distribution, $\mathrm{NB}_{4}$ cells were washed 3 times with cold phosphate-buffered saline (PBS), fixed with $70 \%$ ethanol, and incubated at $-20^{\circ} \mathrm{C}$ for more than $12 \mathrm{~h}$. Before examination, the cells were washed with cold PBS and stained with $0.5 \mathrm{~mL}$ PI staining buffer $(200 \mathrm{mg} / \mathrm{mL}$ RNase A and $50 \mu \mathrm{g} / \mathrm{mL}$ PI in PBS). The mixture was incubated at $37^{\circ} \mathrm{C}$ for $30 \mathrm{~min}$ in the dark, and cell cycle distribution was analyzed by flow cytometry (BD Biosciences). The experiments were repeated 3 times.

2.3. miRNA and mRNA Extraction and Real-Time Quantitative Polymerase Chain Reaction (RTq-PCR). miRNA was extracted with a mirVana miRNA isolation kit (AM1560, Applied Biosystems, Foster City, CA, USA). Mature miR-146a was detected by TaqMan miRNA assay as previously reported [13], using a TaqMan_MicroRNA Reverse Transcription Kit (4366597, Applied Biosystems) and PCR 9700 sequence detection system (Applied Biosystems). U48 was used as an internal control. miRNA levels were expressed as relative $2^{-\Delta \mathrm{CT}}$ values.

mRNAs of other genes (Smad4, PML/RAR $\alpha, A B L$, and GAPDH), excluding miRNAs, were extracted using a QIAampRNA blood mini kit (Qiagen, Valencia, CA, USA), and $10 \mu \mathrm{g}$ mRNA was used in each reverse transcription reaction, carried out with Superscript II reverse transcriptase and random primers (Invitrogen). Gene expression was determined by RTq-PCR as previously described [14] on a PCR 9700 sequence detection system. $A B L$ and $G A P D H$ were used as internal controls. mRNA levels were expressed as relative $2^{-\Delta \mathrm{CT}}$ values.

2.4. Western Blot Analysis. A total of $5 \times 10^{6}$ cells of each experimental group were harvested and subsequently were washed twice with phosphate-buffered saline (PBS). Cells were then lysed with lysis buffer $(300 \mathrm{mM} \mathrm{NaCl}, 0.5 \% \mathrm{NP}-$ 40, $1 \mathrm{mM}$ DTT, $200 \mathrm{mM}$ PMSF, protease inhibitor tablet) for 20 minutes. The protein concentration of the cell lysates was quantified using a bicinchoninic acid (BCA) protein Assay Kit (Kangchen, China). $20 \mu \mathrm{g}$ protein extracted from each experimental sample was separated by sodium dodecyl sulfate-polyacrylamide gel electrophoresis (SDS-PAGE), transferred to polyvinylidene difluoride (PVDF) membranes and blotted with rabbit polyclonal anti-Smad4 (1:5000, Cell Signaling Technology, Danvers, MA, USA) or rabbit monoclonal anti-GAPDH (1:2000, Cell Signaling Technology) antibodies. Protein bands were visualized with the use of enhanced chemiluminescence reagent (Pierce), according to the manufacturer's instructions, and band intensities were analyzed using Bandscan 5.0 (Glyko, Hayward, CA, USA).

\subsection{Patients, Sample Collection, and Therapeutic Methods.} Thirty-two APL patients and ten iron deficiency anemia patients as control who attended Renji Hospital were enrolled in this study. The clinical characteristics of these patients are shown in Table1. Bone marrow was collected from patients at diagnosis or after therapy. APL patients were treated with ATRA $\left(30 \mathrm{mg} / \mathrm{m}^{2}\right)$ and daunorubicin (DNR; $60 \mathrm{mg} / \mathrm{m}^{2}$ )/idarubicin (IDA; $8 \mathrm{mg} / \mathrm{m}^{2}$ ) daily for 3 days. Arsenic trioxide was used at $10 \mathrm{mg}$ daily until patients achieved complete remission. The details of these patients including treatment protocol can be found in Table 2. Protein extracts from 14 patients were used for western blotting, including 6 pairs of samples taken before and after therapy. Written informed consent for participation in this study was 
TABLE 1: Clinical characteristics of APL patients.

\begin{tabular}{lc}
\hline Characteristic & Mean \pm SD \\
\hline Age & $42.22 \pm 2.82$ \\
Gender $($ male/female) & $13 / 19$ \\
WBC count $\left(10^{9} / \mathrm{L}\right)$ & $12.22 \pm 3.45$ \\
BM blast cell percentage $(\%)$ & $84.70 \pm 1.89$ \\
PML/RAR $\alpha$ & $419.81 \pm 48.26$ \\
Th/Ts ratio & $1.48 \pm 0.10$ \\
\hline
\end{tabular}

obtained from all patients. The study was approved by the Ethics Committee of Renji Hospital (number 81270626).

2.6. Statistical Analyses. To investigate whether miR-146a expression correlated with clinical quantitative variables (e.g., WBC counts), we used Pearson correlation analysis within SPSS 16.0 (SPSS Inc., Chicago, IL, USA). The Mann-Whitney $U$ test was carried out to assess the differential expression of $m i R-146 a$ for statistical significance. Data from western blotting were analyzed by paired $t$-tests using SAS version 12.6. All results were presented as the mean \pm standard deviation (SD). $P$ values of less than 0.05 were considered statistically significant.

\section{Results}

3.1. Ectopic Expression of miR-146a Affected Cell Apoptosis and Proliferation but Did Not Affect the Cell Cycle in $\mathrm{NB}_{4}$ Cells Lines. To examine the functional role of miR-146a in APL cells, we transfected miR-146a into $\mathrm{NB}_{4}$ cells and collected the cells $48 \mathrm{~h}$ after transfection. The results showed that forced expression of miR-146a significantly inhibited apoptosis and increased cell viability in $\mathrm{NB}_{4}$ cells, while knockdown of $m i R$ $146 a$ expression using an anti-miR-146a inhibitor increased apoptosis and reduced cell viability significantly (Figures 1(a) and 1(b)). Overexpression of miR-146a in $\mathrm{NB}_{4}$ cells did not affect the cell cycle distribution (Figure 1(c)). The expression of $m i R-146 a$ before and after transfection was confirmed by RTq-PCR (data not shown). Thus, miR-146a may function as an oncogene in leukemogenesis.

\subsection{Exogenous Expression of miR-146a Affected Endogenous} Smad4 Protein Expression in APL Cells. As shown in our previous research, Smad4 protein expression was repressed by more than $30 \%$ in $m i R-146 a$-transfected $293 \mathrm{~T}$ cells [13]. We overexpressed $m i R-146 a$ to confirm the effects of $m i R-146 a$ on Smad4 protein expression in $\mathrm{NB}_{4}$ cells. The results showed that miR-146a significantly reduced Smad4 protein levels but did not affect smad4 mRNA expression, as compared with the scramble control group. In contrast, transfection with miR-146a inhibitor increased Smad4 protein (Figures 2(a) and 2(b)), indicating that miR-146a regulated the expression of Smad4 protein in $\mathrm{NB}_{4}$ cells. To confirm the relation in primary leukemia cells, the expression levels of miR-146a and Smad 4 were examined in 14 APL samples. The results showed that Smad4 expression was inversely correlated with $m i R$ $146 a$ expression in APL samples (Figure 2(c)).
As we previously demonstrated in $\mathrm{NB}_{4}$ cells, ATRA could suppress miR-146a expression, which subsequently increased the expression of Smad4 protein [13]. To study the effects of ATRA on miR-146a and Smad4 expression levels in primary cells, 6 pairs of samples from APL patients before and after ATRA treatment were analyzed. The results showed that miR-146a expression decreased, while Smad4 protein levels increased after treatment with ATRA, as compared to matched samples before therapy (Figure 2(d)).

These data demonstrated that the negative correlation between $m i R-146 a$ and Smad4 protein level may be an indicator of disease progression and treatment outcomes.

3.3. miR-146a Expression Was Associated with the Clinical Characteristics of Patients. Next, we investigated the correlations between $m i R-146 a$ expression and patient characteristics, including age, WBC count, blast cell percentage in the bone marrow or peripheral blood, PML/RAR $\alpha$ expression levels, and Th/Ts ratios. Compared to the controls, we found average $m i R-146 a$ expression levels were higher in APL patients (Figure 3(a)). We found a positive correlation between miR-146a expression and peripheral WBC counts (Figure 3(b)). However, no correlations were found between miR-146a expression and age or blast percentage in peripheral or bone marrow (data not shown).

To investigate the correlations between miR-146a and PML/RAR $\alpha$ and Th/Ts, 32 samples from patients with APL were examined. The results showed that patients with higher miR-146a expression exhibited higher levels of PML/RAR $\alpha$ (Figure 3(c)), but lower Th/Ts ratios (Figure 3(d)).

\section{Discussion}

Recent studies have mainly focused on analyzing the function of miR-146a in hematopoietic cell differentiation; these data have indicated that miR-146a expression is finely tuned during cell differentiation and miR-146a-mediated expression of target genes plays an important role in this process [15]. Moreover, one study demonstrated that overexpression of miR-146a in mouse hematopoietic stem/progenitor cells results in a transient myeloid expansion in vivo [16].

miR-146a and its predicted target gene Smad4 were identified in a previous study using luciferase assays [13]. In our previous study, miR-146a expression was decreased during retinoid acid induction in $\mathrm{NB}_{4}$ cells, accompanied by upregulation of Smad4 protein. These results suggested that miR-146a may play specific roles in APL genesis or ATRAinduced cell differentiation. Elucidating the role of $m i R-146 a$ will improve our understanding of the malignant progression of APL.

In our present study, transfection with miR-146a mimics increased proliferation, while inhibition of miR-146a expression resulted in decreased cell growth and increased apoptosis in $\mathrm{NB}_{4}$ cells. However, ectopic expression of $m i R$ $146 a$ had no effect on cell cycle in $\mathrm{NB}_{4}$ cells. These findings are consistent with several previous studies. Starczynowski et al. investigated the role of miR-146a in hematopoiesis by using retroviral infection and overexpression of miR-146a 
TABLE 2: Clinical variables for controls and APL patients.

\begin{tabular}{|c|c|c|c|c|c|c|c|}
\hline Patients ID & Gender & Age & $\mathrm{WBC}\left(\times 10^{9} / \mathrm{L}\right)$ & PML/RARa: ABL relative ratio & Th/Ts & Smad4/GAPDH & Therapy \\
\hline \multicolumn{8}{|l|}{ Control } \\
\hline $\mathrm{C} 1$ & M & 44 & 6.32 & NA & 0.98 & NA & NA \\
\hline $\mathrm{C} 2$ & $\mathrm{~F}$ & 34 & 4.67 & NA & 1.03 & NA & NA \\
\hline $\mathrm{C} 3$ & $\mathrm{~F}$ & 59 & 5.96 & NA & 0.61 & NA & NA \\
\hline $\mathrm{C} 4$ & $\mathrm{~F}$ & 28 & 11.30 & NA & 1.31 & NA & NA \\
\hline C5 & M & 24 & 8.35 & NA & 1.87 & NA & NA \\
\hline C6 & $\mathrm{F}$ & 63 & 5.90 & NA & 1.55 & NA & NA \\
\hline $\mathrm{C} 7$ & $\mathrm{~F}$ & 30 & 7.40 & NA & 1.07 & NA & NA \\
\hline $\mathrm{C} 8$ & M & 38 & 3.76 & NA & 1.12 & NA & NA \\
\hline C9 & $\mathrm{F}$ & 68 & 7.75 & NA & 2.05 & NA & NA \\
\hline $\mathrm{C} 10$ & M & 35 & 4.81 & NA & 2.11 & NA & NA \\
\hline \multicolumn{8}{|l|}{ APL } \\
\hline A1 & $\mathrm{F}$ & 53 & 0.80 & 174 & 2.03 & 1.4061 & $\mathrm{ATRA}+\mathrm{ATO}+\mathrm{DNR}$ \\
\hline $\mathrm{A} 2$ & $\mathrm{~F}$ & 56 & 3.20 & 285 & 1.69 & 1.2696 & $\mathrm{ATRA}+\mathrm{ATO}+\mathrm{IDA}$ \\
\hline A3 & $\mathrm{F}$ & 67 & 22.40 & 713.5 & 1.01 & 0.7683 & $\mathrm{ATRA}+\mathrm{ATO}+\mathrm{DNR}$ \\
\hline A4 & M & 33 & 6.56 & 493.5 & 1.49 & 0.9575 & $\mathrm{ATRA}+\mathrm{ATO}+\mathrm{IDA}$ \\
\hline A5 & M & 76 & 57.44 & 829.5 & 0.57 & 0.3519 & ATRA + DNR \\
\hline A6 & $\mathrm{F}$ & 33 & 7.50 & 537 & 1.39 & NA & ATRA + DNR \\
\hline A7 & M & 64 & 1.50 & 169 & 1.85 & 1.7688 & $\mathrm{ATRA}+\mathrm{ATO}+\mathrm{IDA}$ \\
\hline A8 & $\mathrm{F}$ & 44 & 2.30 & 416.5 & 1.88 & 1.3570 & $\mathrm{ATRA}+\mathrm{ATO}+\mathrm{IDA}$ \\
\hline A9 & $\mathrm{F}$ & 34 & 3.80 & 434 & 1.72 & NA & $\mathrm{ATRA}+\mathrm{ATO}+\mathrm{IDA}$ \\
\hline A10 & $\mathrm{F}$ & 63 & 6.30 & 501.5 & 0.97 & 1.1272 & $\mathrm{ATRA}+\mathrm{ATO}+\mathrm{IDA}$ \\
\hline A11 & M & 28 & 64.60 & 1048 & 0.36 & 0.2464 & ATRA \\
\hline A12 & $\mathrm{F}$ & 24 & 1.05 & 225.5 & 1.95 & NA & $\mathrm{ATRA}+\mathrm{ATO}+\mathrm{IDA}$ \\
\hline A13 & $\mathrm{F}$ & 24 & 1.60 & 143 & 1.8 & 2.0794 & $\mathrm{ATRA}+\mathrm{ATO}+\mathrm{IDA}$ \\
\hline A14 & M & 30 & 7.60 & 221 & 1.61 & 0.8966 & $\mathrm{ATRA}+\mathrm{ATO}+\mathrm{IDA}$ \\
\hline A15 & $\mathrm{F}$ & 38 & 34.10 & 617 & 0.49 & NA & ATRA + DNR \\
\hline A16 & M & 21 & 2.30 & 378 & 1.15 & NA & $\mathrm{ATRA}+\mathrm{ATO}+\mathrm{DNR}$ \\
\hline A17 & $\mathrm{F}$ & 23 & 0.70 & 183 & 2 & 1.5293 & ATRA + DNR \\
\hline A18 & M & 48 & 2.60 & 331 & 1.27 & NA & ATRA + DNR \\
\hline A19 & $\mathrm{F}$ & 24 & 3.90 & 411 & 1.86 & NA & $\mathrm{ATRA}+\mathrm{ATO}+\mathrm{IDA}$ \\
\hline A20 & $\mathrm{F}$ & 34 & 9.70 & 612 & 1.31 & NA & $\mathrm{ATRA}+\mathrm{ATO}+\mathrm{DNR}$ \\
\hline A21 & $\mathrm{F}$ & 60 & 1.30 & 173 & 1.87 & 1.9294 & $\mathrm{ATRA}+\mathrm{ATO}+\mathrm{IDA}$ \\
\hline A22 & $\mathrm{F}$ & 50 & 1.60 & 199 & 1.91 & NA & $\mathrm{ATRA}+\mathrm{ATO}+\mathrm{IDA}$ \\
\hline A23 & M & 30 & 1.60 & 189 & 1.85 & NA & $\mathrm{ATRA}+\mathrm{ATO}+\mathrm{IDA}$ \\
\hline A24 & $\mathrm{F}$ & 56 & 1.10 & 191 & 1.99 & NA & $\mathrm{ATRA}+\mathrm{ATO}+\mathrm{IDA}$ \\
\hline A25 & M & 51 & 3.20 & 367 & 1.7 & NA & ATRA + ATO + IDA \\
\hline A26 & $\mathrm{F}$ & 24 & 2.20 & 336 & 1.91 & NA & $\mathrm{ATRA}+\mathrm{ATO}+\mathrm{IDA}$ \\
\hline $\mathrm{A} 27$ & M & 40 & 1.00 & 156 & 1.97 & NA & ATRA + ATO + IDA \\
\hline A28 & M & 15 & 28.30 & 729 & 0.93 & NA & $\mathrm{ATRA}+\mathrm{ATO}+\mathrm{IDA}$ \\
\hline A29 & $\mathrm{F}$ & 62 & 0.60 & 201 & 2.13 & NA & $\mathrm{ATRA}+\mathrm{ATO}+\mathrm{DNR}$ \\
\hline A30 & M & 50 & 41.40 & 854 & 0.64 & NA & $\mathrm{ATRA}+\mathrm{ATO}+\mathrm{IDA}$ \\
\hline A31 & $\mathrm{F}$ & 44 & 67.20 & 1137 & 0.3 & 0.3373 & $\mathrm{ATRA}+\mathrm{ATO}+\mathrm{IDA}$ \\
\hline A32 & M & 52 & 1.50 & 179 & 1.82 & NA & $\mathrm{ATRA}+\mathrm{ATO}+\mathrm{IDA}$ \\
\hline
\end{tabular}

M: male; F: female; WBC: white blood cell; ATRA: all trans retinoic acid; ATO: arsenic trioxide; DNR: daunorubicin; IDA: idarubicin; NA: not available.

in mouse hematopoietic stem/progenitor cells, followed by bone marrow transplantations. The transplantation of these cells resulted in a transient myeloid expansion [16]. Moreover, $m i R-146 a$ has been found to play an antiapoptotic role during $\mathrm{T}$ cell activation [17].
Some other results were inconsistent with our results. Overexpression $m i R-146 a$ in hepatic stellate cell (HSC) inhibited cell proliferation by enhancing cell apoptosis [18]. Treating HL60 cells with demethylating agents increased $m i R-146 a$ expression, and forced expression of $m i R-146 a$ decreases cell 

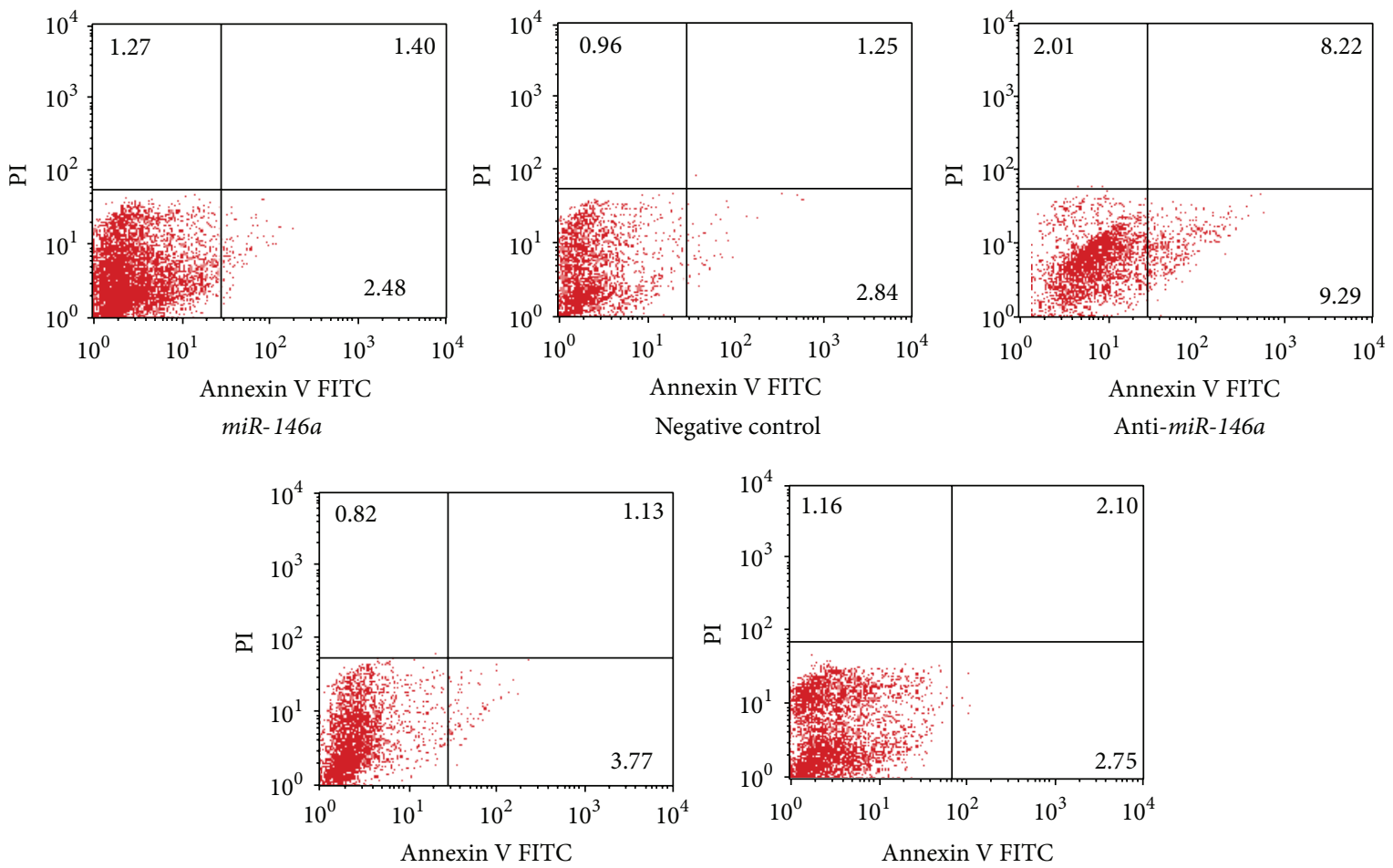

Anti-negative control
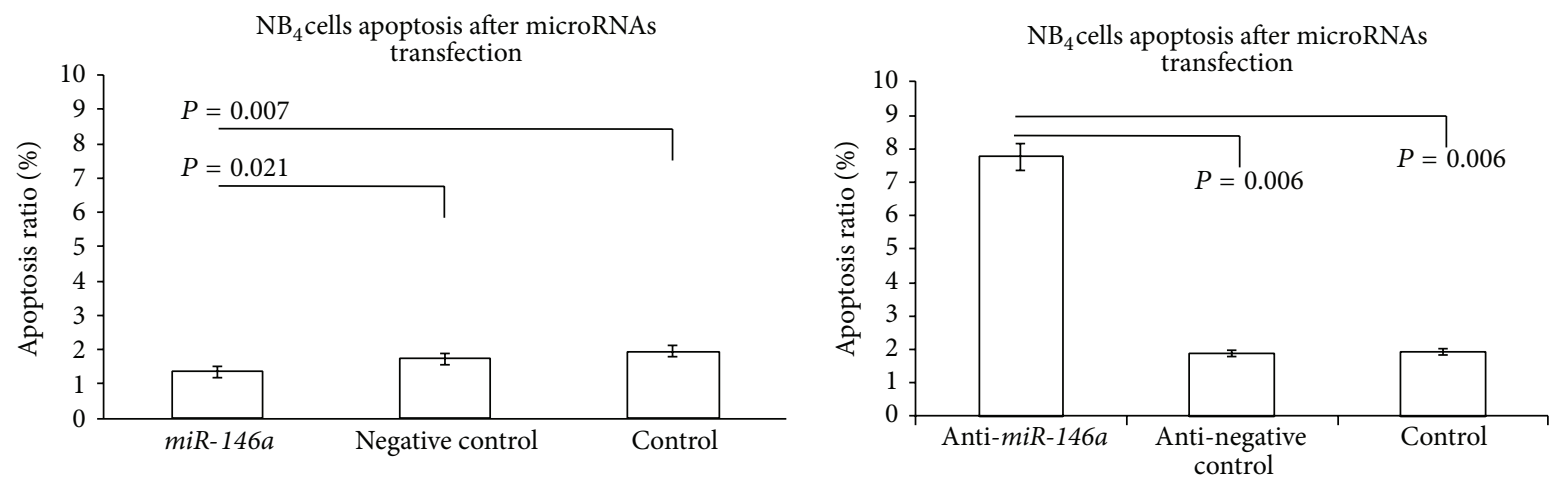

(a)
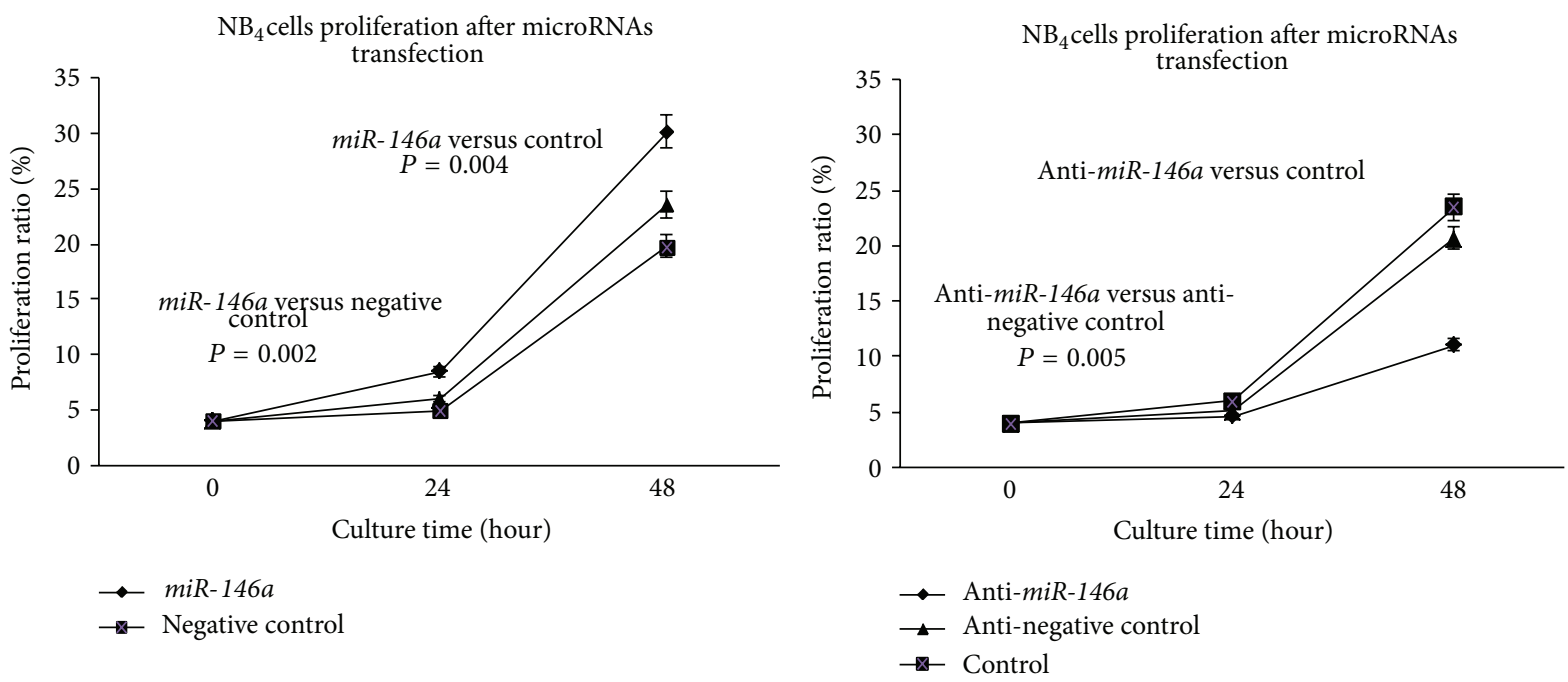

(b)

Figure 1: Continued. 


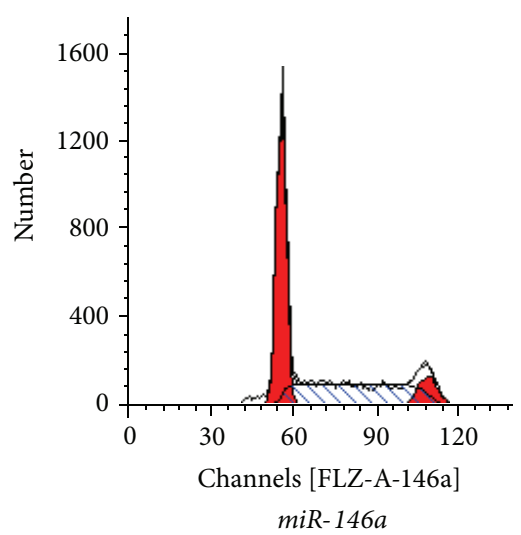

$\operatorname{miR}-146 a$

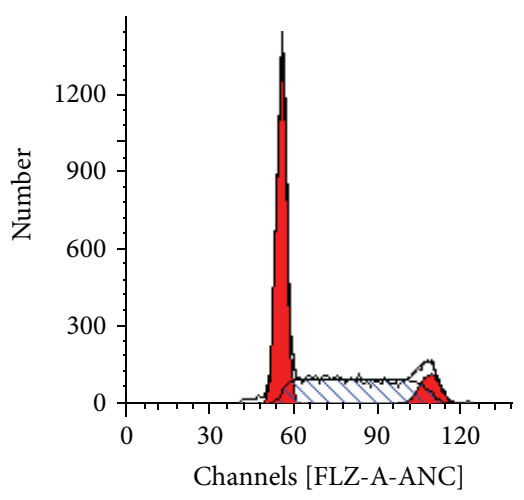

Negative control

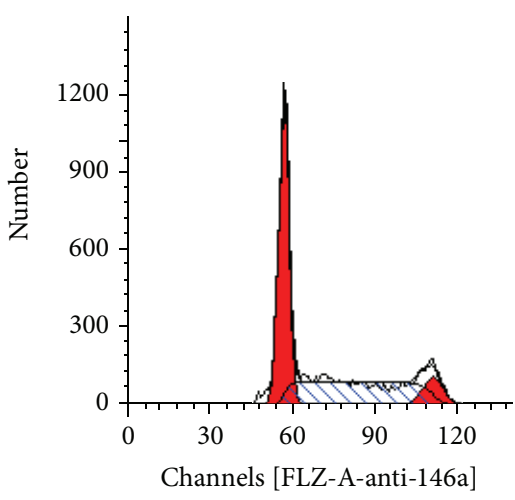

Anti-miR-146a
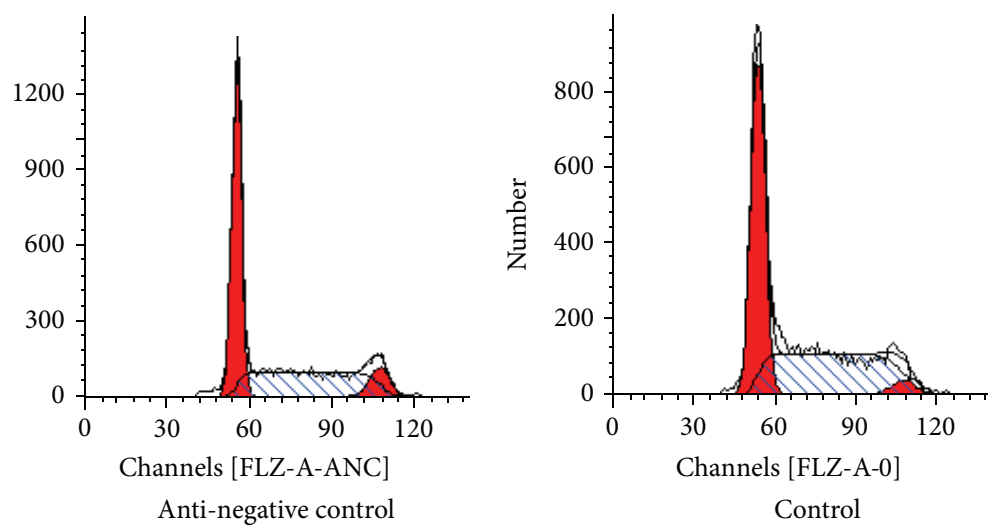

(c)

FIGURE 1: The functional role of miR-146a. (a) Forced expression of miR-146a by transfection of cells with pre-miR-146a with lipidosome significantly inhibited apoptosis, whereas downregulation of $m i R-146 a$ by anti-pre-miR miR-146a inhibitor significantly increased apoptosis in $\mathrm{NB}_{4}$ cells. (b) Forced expression of miR-146a significantly increased, whereas downregulation of miR-146a significantly decreased cell proliferation in $\mathrm{NB}_{4}$ cells. (c) The cell cycle was not affected after ectopic expression of miR-146a. Normalized mean values of 3 independent experiments and standard errors (means \pm SDs) are shown. ${ }^{*}, P \leq 0.05 ;^{* *}, P \leq 0.001$ (paired $t$ test).

proliferation in HL60 cells [19]. Chen et al. also showed that miR-146a was upregulated during phorbol 12-myristate 13acetate (TPA)-induced differentiation of HL-60 cells [20]. $m i R-146 a$ has also been shown to be important in the development and maintenance of cancers, including anaplastic thyroid cancer, pancreatic carcinoma, gastric cancer, breast cancer, prostate cancer, glioma, and cervical cancer [21-28]. All of these data show miR-146a expression, function, and regulation in cancers or hematopoietic malignancies may vary in terms of the types of tissues or cells affected. Additionally, $m i R-146 a$ expression in different cancers or tissues is thought to be regulated primarily by point mutations, histone deacetylation, or promoter methylation [29].

The transforming growth factor (TGF)- $\beta$ signaling pathway and its downstream target proteins, including Smads, are known to repress cell proliferation in leukemia cells. Inactivation of the TGF- $\beta /$ Smad signaling pathway can induce the development of leukemia in humans. Smad4 is the only Co-Smad that has been identified in mammals and is known to play a key role in the TGF- $\beta 1 / \mathrm{Smad}$ signaling cascade [30]. Furthermore, mutations in Smad4 can block nuclear translocation of this gene, which is associated with the pathogenesis of acute myelogenous leukemia [31]. Our data showed that transient transfection with miR-146a mimics suppressed Smad4 protein expression in $\mathrm{NB}_{4}$ cells, while transfection with an miR-146a inhibitor increased Smad4 protein expression in these cells. Like other miRNAs, miR$146 a$ can modulate cellular activities, such as cell proliferation, differentiation, and migration, by targeting mRNAs encoding specific proteins. Overexpression of miR-146a in a model of osteoarthritis (OA) was accompanied by downregulation of Smad4 in vivo [32]. In this OA model study, $m i R-146 a$ was proposed to contribute to OA pathogenesis by impairing the TGF- $\beta$ signaling pathway through targeted inhibition of Smad4 in cartilage [32]. Interestingly, miR-146a overexpression in HSC can also reduce Smad4 protein levels without affecting its mRNA expression [18]. These discoveries have provided insights contributing to our understanding of the mechanisms involved in miR-146a/Smad4 signaling transduction.

miR-146a expression is significantly downregulated during monocytic differentiation in $\mathrm{NB}_{4}$ cells in response to chemical inducers vitamin $\mathrm{D}$ and phorbol 12-myristate 13acetate (PMA) [33]. Our previous study showed that miR$146 a$ is downregulated during $\mathrm{NB}_{4}$ differentiation induced by ATRA [13]. In the current study, miR-146a expression 


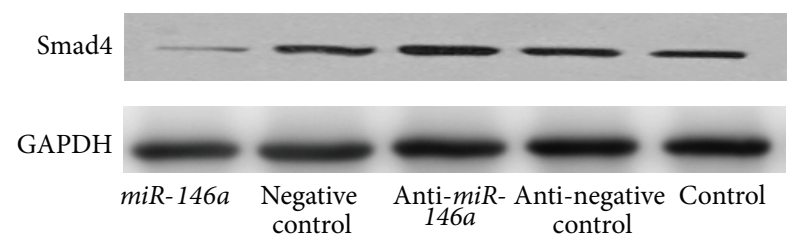

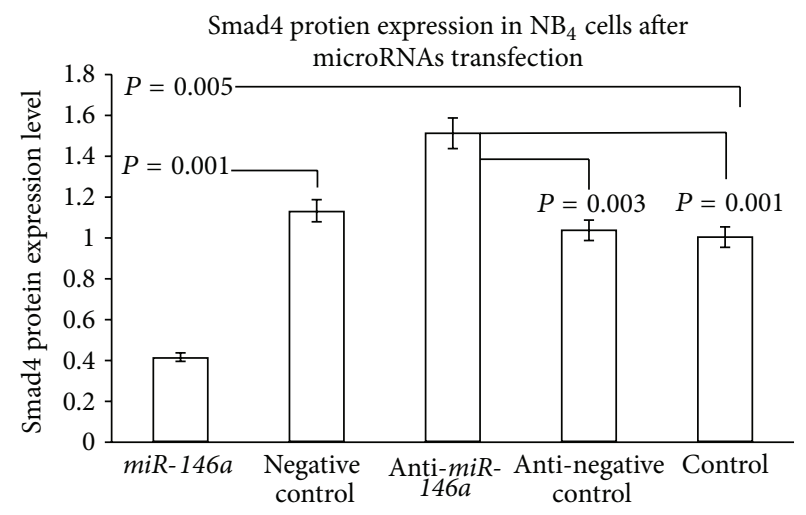

(a)

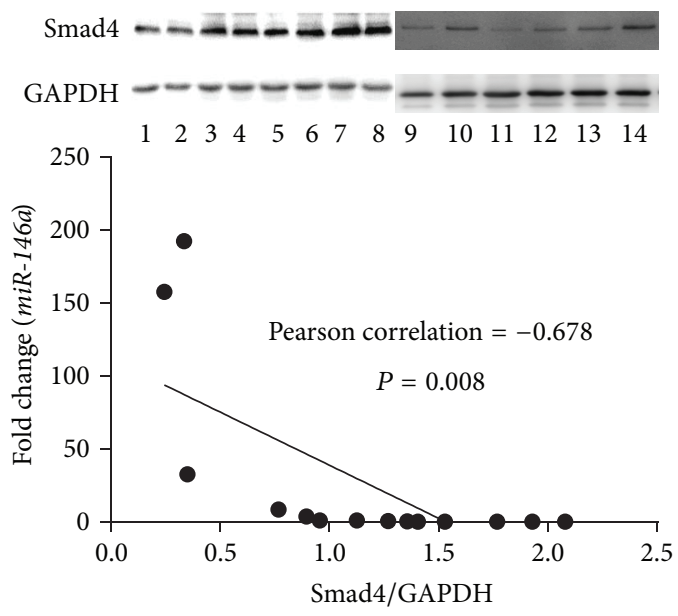

(c)

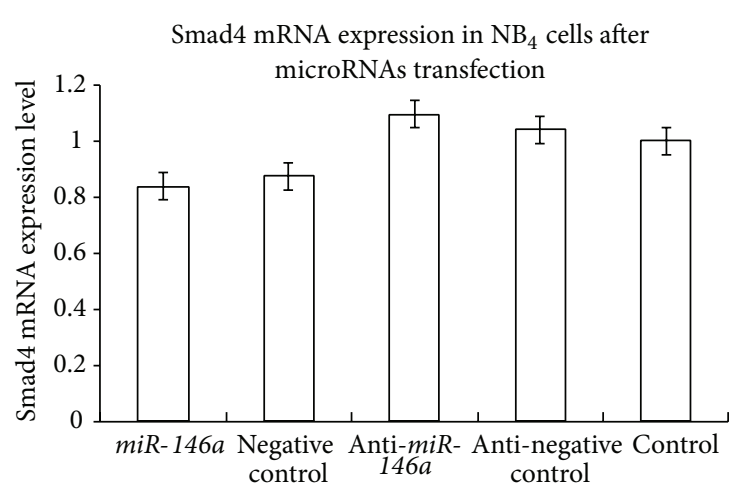

(b)

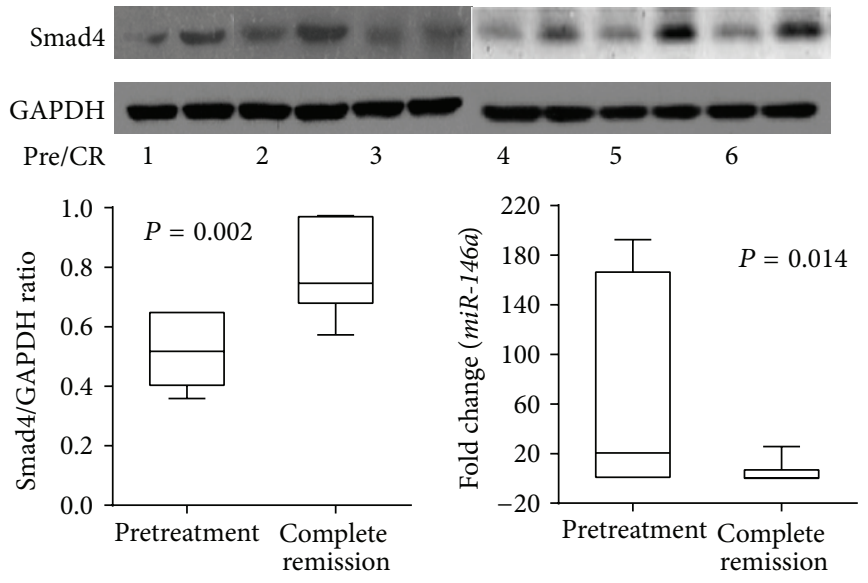

(d)

Figure 2: Exogenous miR-146a and endogenous Smad4 expression. (a) Western blot analysis of Smad4 protein expression in $\mathrm{NB}_{4}$ cells after transfection with $m i R-146 a$ duplex, miR-146a inhibitor duplex, or scrambled duplex. (b) RTq-PCR analysis of Smad4 gene expression in $\mathrm{NB}_{4}$ cells after transfection with miR-146a duplex, miR-146a inhibitor duplex, or scrambled duplex. (c) miR-146a was inversely correlated with Smad4 protein expression in samples from 14 APL patients. (d) miR-146a and Smad4 protein expression analysis in samples from 6 APL patients at diagnosis and after complete remission using RTq-PCR and western blotting. Normalized mean values of 3 independent experiments and standard errors (means $\pm \mathrm{SDs}$ ) are shown. ${ }^{*}, P \leq 0.05 ;^{* *}, P \leq 0.001$ (paired $t$ test).

was decreased, accompanied by increased Smad4 protein expression in APL patients exhibiting complete remission. These data suggested that miR-146a expression was correlated with APL cell differentiation.

In our analysis, miR-146a was found to be positively correlated with WBC counts in patients, which is consistent with our in vitro data. In another study, miR-146a was overexpressed in hematopoietic stem cells, and the modified cells were then transplanted into recipients' bone marrow. Transplantation of these cells resulted in a transient myeloid expansion [16]. This result also showed that $m i R-146 a$ indeed affected cell proliferation. PML/RAR $\alpha$ complexes can bind to the predicted PML/RAR $\alpha$ binding site in the promoter region of $m i R-146 a$, and the repressive effects of PML/RAR $\alpha$ complexes can be blocked by ATRA, even in primary blast cells [11]. In our study, expression of the PML/RAR $\alpha$ fusion gene was decreased after patients achieved complete remission following retinoid acid induction, and $m i R-146 a$ expression decreased simultaneously, indicating that $m i R$ $146 a$ was regulated by PML/RAR $\alpha$ in the leukemogenesis of APL.

miR-146a is abundantly expressed in regulatory $\mathrm{T}$ cells and $\mathrm{T}$ helper type- 1 cells as compared with naïve mature $\mathrm{T}$ cells and T helper type-2 [34]. miR-146a contributes to the 


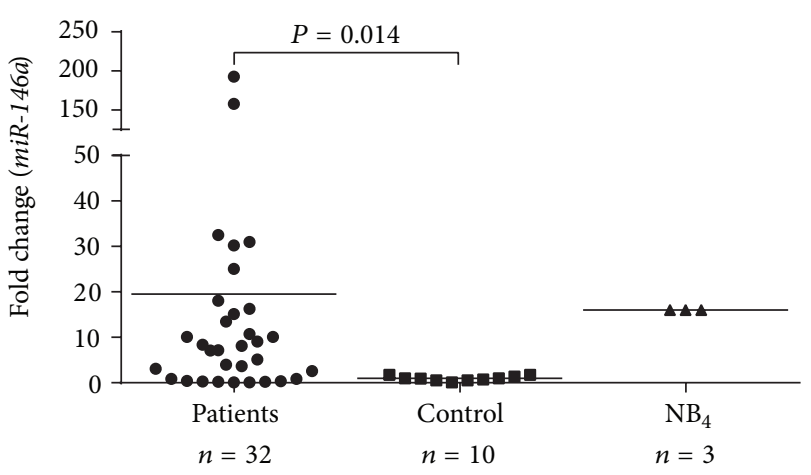

(a)

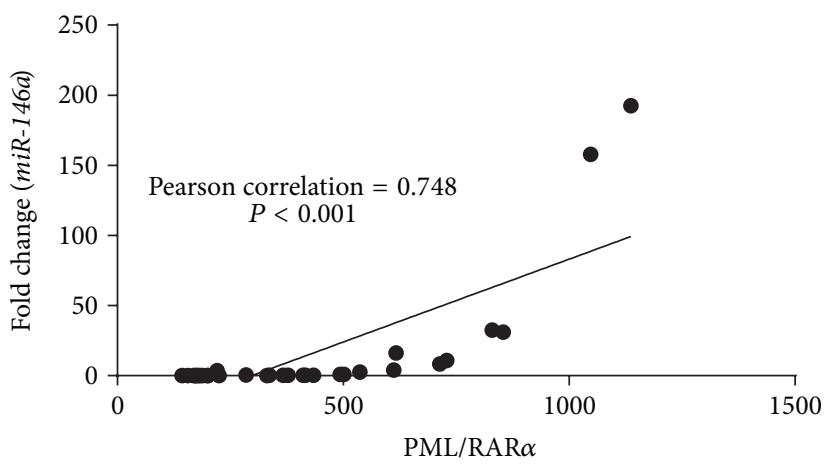

(c)

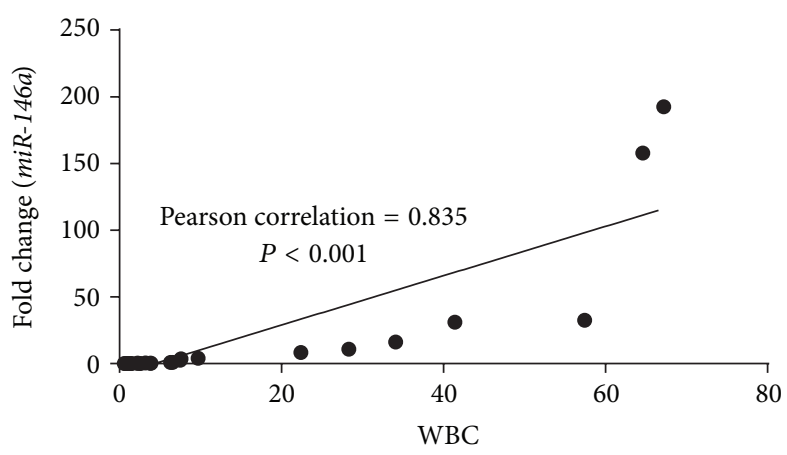

(b)

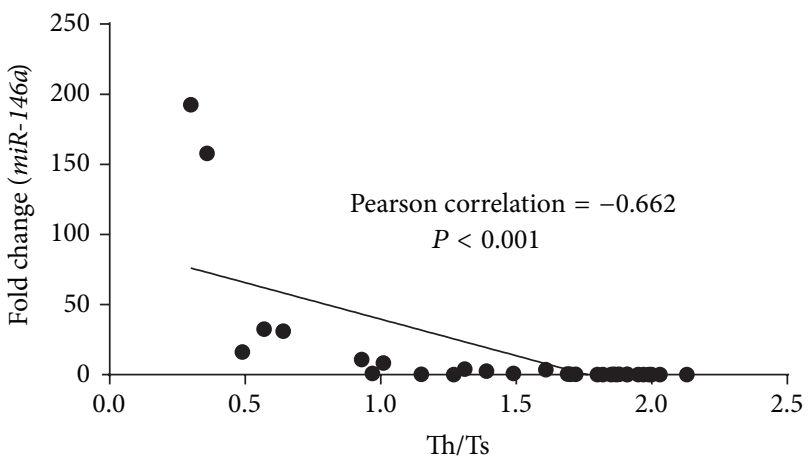

(d)

FiguRE 3: miR-146a expression and clinical characteristics of 32 patients. (a) miR-146a levels in APL patients, controls, and $\mathrm{NB}_{4}$ cells. (b) $m i R-146 a$ levels were positively correlated with white blood cell (WBC) counts. (c) miR-146a was positively correlated with PML/RAR $\alpha$ gene expression. (d) $m i R-146 a$ expression was negatively correlated with the $\mathrm{Th} / \mathrm{Ts}$ ratio.

regulation of the type I interferon signal transduction pathway, which is important for immune surveillance [17, 21]. Our data showed a negative correlation between $m i R-146 a$ and the Th/Ts ratio in APL patients (Figure 3(c)), suggesting that overexpression of miR-146a may impair immune surveillance in APL patients.

In conclusion, our data demonstrated that miR-146a played an important role in APL cells by increasing cell proliferation and inhibiting cell apoptosis, at least in part via the tumor-suppressor Smad4. miR-146a expression was associated with peripheral WBC counts, Th/Ts ratios, and PML/RAR $\alpha$ expression levels in APL patients, suggesting that $m i R-146 a$ may represent a novel biomarker for APL and could be used to evaluate the effectiveness of chemotherapy for APL.

\section{Conflict of Interests}

The authors declare that they have no conflict of interests.

\section{Acknowledgments}

This work was supported by Grants from the National Natural Science Foundation of China (81270626), Shanghai Municipal Commission of Sciences and Technology Fund
(09ZR1418400), and Key Discipline Project of Renji Hospital, Shanghai Jiaotong University School of Medicine (RJ 4101306). Informed consent was obtained from all patients in this study.

\section{References}

[1] J. M. Bennett, D. Catovsky, M. T. Daniel et al., "Proposals for the classification of the acute leukaemias," British Journal of Haematology, vol. 33, no. 4, pp. 451-458, 1976.

[2] H. de The, C. Lavau, A. Marchio, C. Chomienne, L. Degos, and A. Dejean, "The PML-RAR $\alpha$ fusion mRNA generated by the $t(15 ; 17)$ translocation in acute promyelocytic leukemia encodes a functionally altered RAR," Cell, vol. 66, no. 4, pp. 675-684, 1991.

[3] M. S. Tallman, C. Nabhan, J. H. Feusner, and J. M. Rowe, "Acute promyelocytic leukemia: Evolving therapeutic strategies," Blood, vol. 99, no. 3, pp. 759-767, 2002.

[4] C. M. Croce and G. A. Calin, "miRNAs, cancer, and stem cell division," Cell, vol. 122, no. 1, pp. 6-7, 2005.

[5] V. Ambros, "MicroRNA pathways in flies and worms: growth, death, fat, stress, and timing," Cell, vol. 113, no. 6, pp. 673-676, 2003.

[6] K. D. Taganov, M. P. Boldin, K. Chang, and D. Baltimore, "NF$\kappa \mathrm{B}$-dependent induction of microRNA miR-146, an inhibitor targeted to signaling proteins of innate immune responses," Proceedings of the National Academy of Sciences of the United States of America, vol. 103, no. 33, pp. 12481-12486, 2006. 
[7] R. Garzon, S. Volinia, C. G. Liu et al., "MicroRNA signatures associated with cytogenetics and prognosis in acute myeloid leukemia," Blood, vol. 111, no. 6, pp. 3183-3189, 2008.

[8] J. B. Opalinska, A. Bersenev, Z. Zhang et al., "MicroRNA expression in maturing murine megakaryocytes," Blood, vol. 116, no. 23, pp. e128-e138, 2010.

[9] F. Fazi, A. Rosa, A. Fatica et al., "A minicircuitry comprised of microRNA-223 and transcription factors NFI-A and C/EBP $\alpha$ regulates human granulopoiesis," Cell, vol. 123, no. 5, pp. 819831, 2005.

[10] R. Garzon, F. Pichiorri, T. Palumbo et al., "MicroRNA gene expression during retinoic acid-induced differentiation of human acute promyelocytic leukemia," Oncogene, vol. 26, no. 28, pp. 4148-4157, 2007.

[11] A. Saumet, G. Vetter, M. Bouttier et al., "Transcriptional repression of microRNA genes by PML-RARA increases expression of key cancer proteins in acute promyelocytic leukemia," Blood, vol. 113, no. 2, pp. 412-421, 2009.

[12] M. L. de Marchis, M. Ballarino, B. Salvatori, M. C. Puzzolo, I. Bozzoni, and A. Fatica, "A new molecular network comprising PU.1, interferon regulatory factor proteins and miR342 stimulates ATRA-mediated granulocytic differentiation of acute promyelocytic leukemia cells," Leukemia, vol. 23, no. 5, pp. 856-862, 2009.

[13] H. Zhong, H. Wang, S. Yang et al., "Targeting Smad4 links microRNA-146a to the TGF- $\beta$ pathway during retinoid acid induction in acute promyelocytic leukemia cell line," International Journal of Hematology, vol. 92, no. 1, pp. 129-135, 2010.

[14] G. Visani, S. Buonamici, M. Malagola et al., "Pulsed ATRA as single therapy restores long-term remission in PML-RAR $\alpha$ positive acute promyelocytic leukemia patients: real time quantification of minimal residual disease. A pilot study," Leukemia, vol. 15, no. 11, pp. 1696-1700, 2001.

[15] R. M. O'Connell, J. L. Zhao, and D. S. Rao, "MicroRNA function in myeloid biology," Blood, vol. 118, no. 11, pp. 2960-2969, 2011.

[16] D. T. Starczynowski, F. Kuchenbauer, J. Wegrzyn et al., "MicroRNA-146a disrupts hematopoietic differentiation and survival," Experimental Hematology, vol. 39, no. 2, pp. 167.e4178.e4, 2011.

[17] G. Curtale, F. Citarella, C. Carissimi et al., "An emerging player in the adaptive immune response: MicroRNA-146a is a modulator of IL-2 expression and activation-induced cell death in T lymphocytes," Blood, vol. 115, no. 2, pp. 265-273, 2010.

[18] Y. He, C. Huang, X. Sun, X.-R. Long, X.-W. Lv, and J. Li, "MicroRNA-146a modulates TGF-betal-induced hepatic stellate cell proliferation by targeting SMAD4," Cellular Signalling, vol. 24, no. 10, pp. 1923-1930, 2012.

[19] D. T. Starczynowski, R. Morin, A. McPherson et al., "Genomewide identification of human microRNAs located in leukemiaassociated genomic alterations," Blood, vol. 117, no. 2, pp. 595607, 2011.

[20] A. Chen, M. Luo, G. Yuan et al., "Complementary analysis of microRNA and mRNA expression during phorbol 12myristate 13-acetate (TPA)-induced differentiation of HL-60 cells," Biotechnology Letters, vol. 30, no. 12, pp. 2045-2052, 2008.

[21] C. Labbaye and U. Testa, "The emerging role of MIR-146A in the control of hematopoiesis, immune function and cancer," Journal of Hematology and Oncology, vol. 5, article 13, 2012.

[22] F. Pacifico, E. Crescenzi, S. Mellone et al., "Nuclear factor$\kappa \mathrm{b}$ contributes to anaplastic thyroid carcinomas through upregulation of miR-146a," Journal of Clinical Endocrinology and Metabolism, vol. 95, no. 3, pp. 1421-1430, 2010.
[23] L. Li, X.-P. Chen, and Y.-J. Li, "MicroRNA-146a and human disease," Scandinavian Journal of Immunology, vol. 71, no. 4, pp. 227-231, 2010.

[24] R. Kogo, K. Mimori, F. Tanaka, S. Komune, and M. Mori, "Clinical significance of miR-146a in gastric cancer cases," Clinical Cancer Research, vol. 17, no. 13, pp. 4277-4284, 2011.

[25] D. R. Hurst, M. D. Edmonds, G. K. Scott, C. C. Benz, K. S. Vaidya, and D. R. Welch, "Breast cancer metastasis suppressor 1 up-regulates miR-146, Which suppresses breast cancer metastasis," Cancer Research, vol. 69, no. 4, pp. 1279-1283, 2009.

[26] S. L. Lin, A. Chiang, D. Chang, and S. Ying, "Loss of mir-146a function in hormone-refractory prostate cancer," $R N A$, vol. 14, no. 3, pp. 417-424, 2008.

[27] J. Mei, R. Bachoo, and C. Zhang, "MicroRNA-146a inhibits glioma development by targeting Notchl," Molecular and Cellular Biology, vol. 31, no. 17, pp. 3584-3592, 2011.

[28] X. Wang, S. Tang, S. Y. Le et al., "Aberrant expression of oncogenic and tumor-suppressive microRNAs in cervical cancer is required for cancer cell growth," PLoS ONE, vol. 3, no. 7, Article ID e2557, 2008.

[29] G. A. Calin and C. M. Croce, "MicroRNA signatures in human cancers," Nature Reviews Cancer, vol. 6, no. 11, pp. 857-866, 2006.

[30] I. Isufi, M. Seetharam, L. Zhou et al., "Transforming growth factor- $\beta$ signaling in normal and malignant hematopoiesis," Journal of Interferon and Cytokine Research, vol. 27, no. 7, pp. 543-552, 2007.

[31] Y. Imai, M. Kurokawa, K. Izutsu et al., "Mutations of the Smad4 gene in acute myelogeneous leukemia and their functional implications in leukemogenesis," Oncogene, vol. 20, no. 1, pp. 88-96, 2001.

[32] J. Li, J. Huang, L. Dai et al., "MiR-146a, an IL-1beta responsive miRNA, induces vascular endothelial growth factor and chondrocyte apoptosis by targeting Smad4," Arthritis Research and Therapy, vol. 14, no. 2, p. R75, 2012.

[33] M. Lutherborrow, A. Bryant, V. Jayaswal et al., "Expression profiling of cytogenetically normal acute myeloid leukemia identifies MicroRNAs that target genes involved in monocytic differentiation," American Journal of Hematology, vol. 86, no. 1, pp. 2-11, 2011.

[34] S. Monticelli, K. M. Ansel, C. Xiao et al., "MicroRNA profiling of the murine hematopoietic system," Genome Biology, vol. 6, no. 8, p. R71, 2005. 


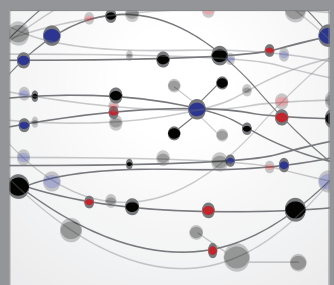

The Scientific World Journal
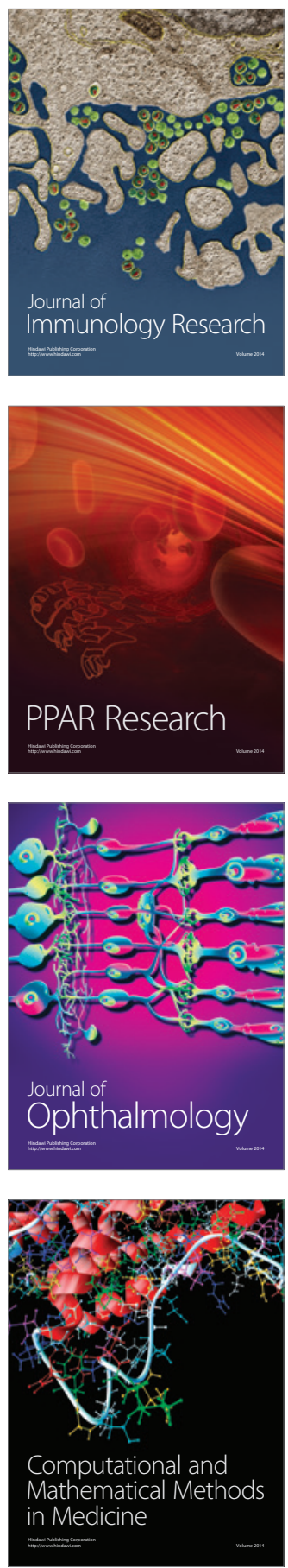

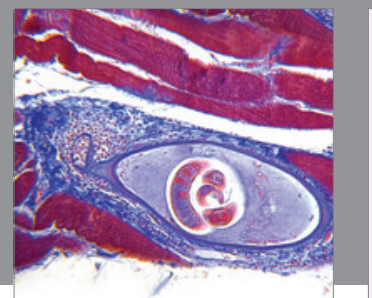

Gastroenterology

Research and Practice
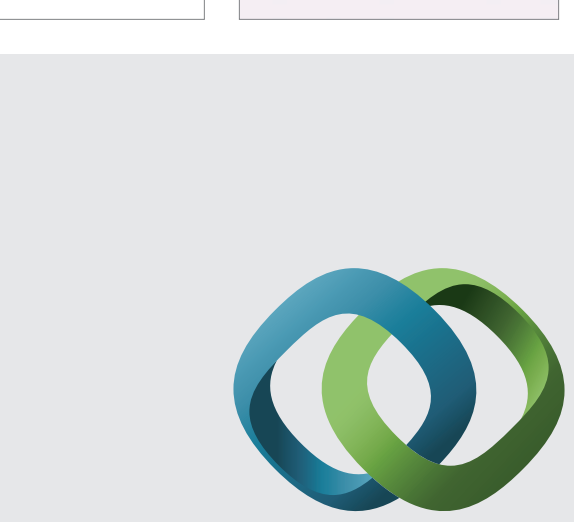

\section{Hindawi}

Submit your manuscripts at

http://www.hindawi.com
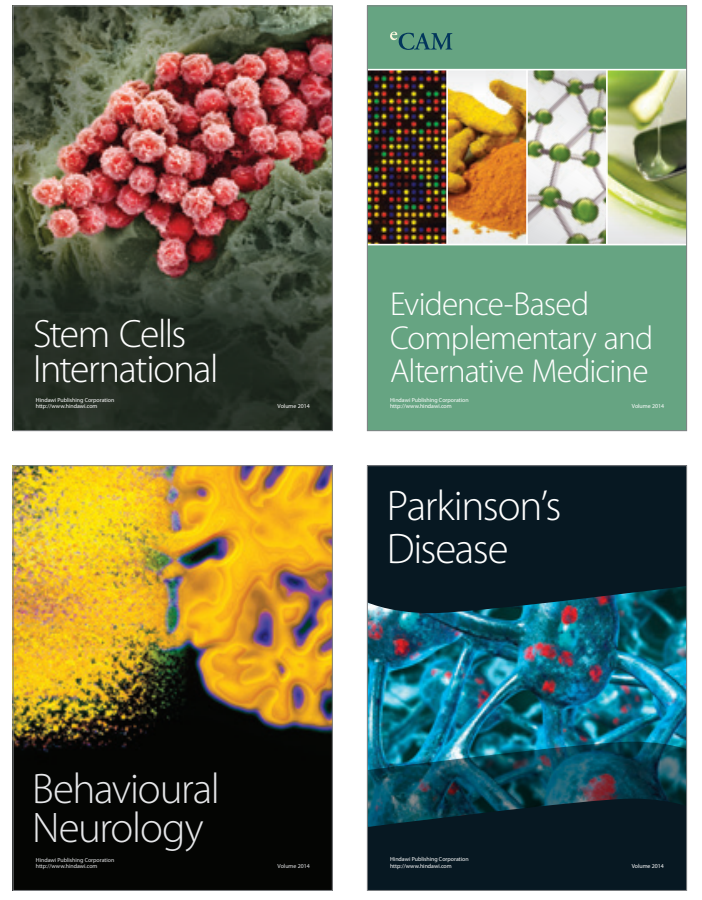
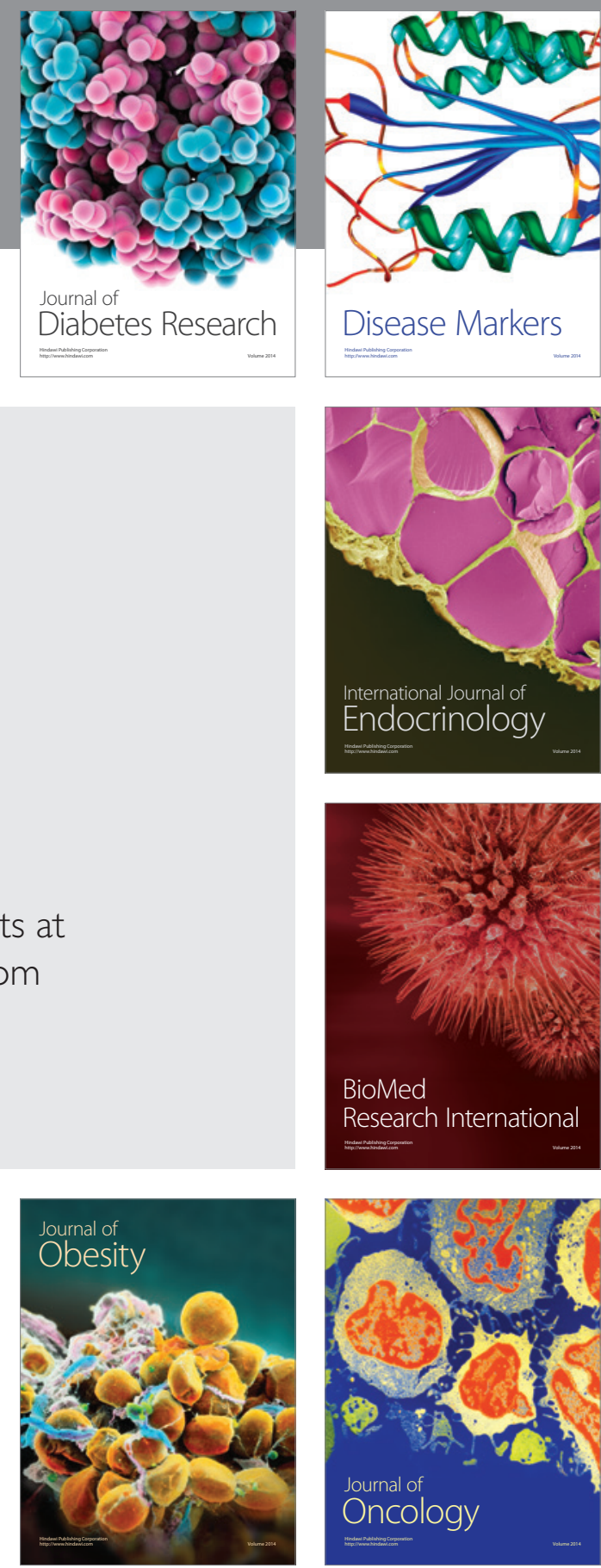

Disease Markers
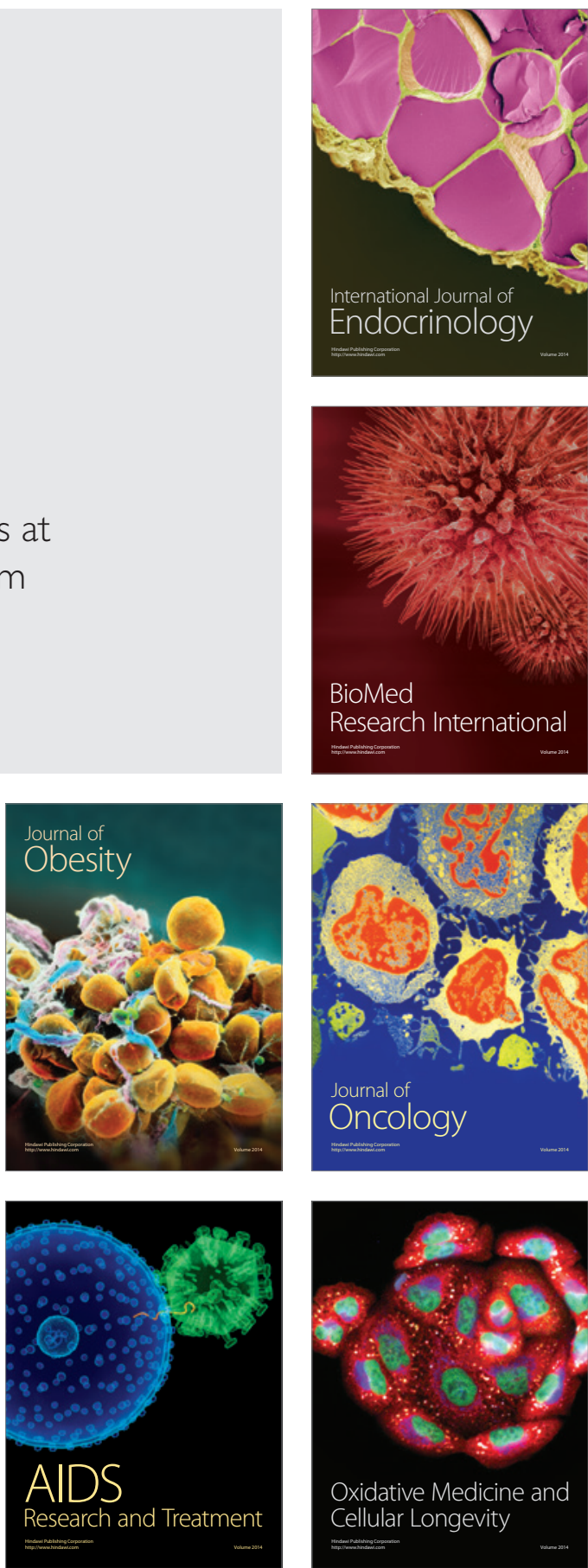